\title{
Research on Regional Differences of Monetary Effect in China -- Based on the Analysis of VAR Model
}

\author{
Ya-hui ZHANG ${ }^{1, a,{ }^{*}}$ \\ ${ }^{1}$ School of Economics and Management, Nanjing University of Science and \\ Technology, China \\ a920328281@qq.com \\ ${ }^{*}$ Corresponding author
}

Keywords: Regional Effect of Monetary Policy, Nsmission mechanisms, VAR model.

\begin{abstract}
In recent years, China's national economy has developed rapidly. However, the current situation of uneven economic development in various regions of our country cannot be ignored. Monetary policy as a means of macro-control has an important role in regulating the economy. This paper chooses the regional research of monetary policy transmission in China to analyze the current situation of economic imbalance. Through theoretical analysis and Empirical Study Based on VAR model, to verify the existence of regional differences of monetary policy in China, and put forward some suggestions
\end{abstract}

\section{Introduction}

Monetary policy, as one of the most important macroeconomic management measures, is of great significance to the national economy. The government usually pay more attention to the overall development of the national economy, inconsistent and less consideration of regional economic development, so the development and implementation of unity within a country's monetary policy is not reasonable, it will cause a series of adverse effects, not only affect the middle bank's monetary policy target, may also further expand the level of the economic development gap between regions. Therefore, it can improve the effectiveness of China's monetary policy in the light of the existence, measurement and analysis of the regional differences of monetary policy effects

The study of the regional asymmetric effects of monetary policy is mainly concentrated in some large countries, and the most abundant research results in the United states. Fishkind (1977) found that the Fed's monetary policy on Indiana's economy compared with the impact of the country are different, and that this asymmetry is mainly caused by the relative economic structure of Indiana.

Due to labor and other factors of production can not flow freely, China's regional economic openness, financial structure, industrial structure are different, which makes China does not meet the criteria of the optimal currency area. Therefore, in theory, there are regional differences in the effects of monetary policy in china. Ba (2000) believes that as the difference of economic level between eastern and western regions of China, the unified monetary policy implied by the middle bank will lead to the effects of monetary policy and different objectives, reduce the effectiveness of monetary policy. Based on the theory of optimum currency area, Ke (2001), Jia (2004), and $\mathrm{Ma}(2005)$ think that China, as a single currency area, has not reached the optimal currency area. Based on the analysis of rational expectation, Wu etl.(2005) think that the difference of regional information and the degree of knowledge rationality of market participants are the important reasons for the regional differences 
of monetary policy..Ding (2005) used the dynamic distributed lag model based on Phillips - Tan, the cointegration test and the Granger causality test to prove the existence of the regional asymmetric effect of monetary policy. Yu (2007) and Cao(2007) divided the region of China into East, West, northeast, and Beijing-Tianjin-Hebei five regions and eight regions, using fixed effect variable coefficient model to estimate monetary policy sensitive coefficient eight regions, and further using structural vector autoregressive (SVAR) model and structural variance the decomposition method to analyses the impact of monetary shocks on regional economy.

This paper based on prior research, using the new data, divided the region into three major regions of China(according to the National Bureau of Statistics Division ), Based on the VAR model to study the regional differences of on China's monetary effects, and try to analyze the reasons, and last put forward some policy suggestions.

\section{Data}

The conduction of monetary policy begins with the choice of correct monetary policy tools and the intermediate target of monetary policy. China's monetary policy transmission channel is mainly based on credit transmission, and China has not yet completed the interest rate market. So in this paper, the broad money supply M2 is chosen to reflect the monetary policy of our country. The transmission of monetary policy ultimately depends on the actual economic effects of monetary policy, which can be reflected by economic development and price changes. So we choose the GDP and CPI to measure the output effect and price effect.

The data in this paper cover the annual data from 1995 to 2014. According to the criterion of National Bureau of Statistics, we divide the region of China into three region-the eastern region, the western region and the middle region.

The basic data of GDP, CPI and M2 is from the National Bureau of Statistics website. The GDP of each region is the sum of every province's GDP in this region and the CPI is the average of every province. In order to eliminate the heteroscedasticity of the data and avoid the fluctuation of the data, we deal with the logarithm of the data. For convenient, we record the data in eastern, western and middle region as $\operatorname{lnM} 2$, lnGDPE, lnGDPM, lnGDPW, lnCPIE, lnCPIM, lnCPIW

\section{Empirical Test}

\section{ADF Test}

Before the stability of ADF test of the time series, we need to first observe the sequence diagram of each variable and to determine whether the intercept and trend. The ADF test of 3 regions of the money supply, GDP and CPI results are shown in Table 1 
Table 1. ADF unit root test

\begin{tabular}{|c|c|c|c|c|c|}
\hline Varience & Type & ADF & $5 \%$ Critical value & P value & Stability \\
\hline M2 & $(\mathrm{c}, \mathrm{t}, 3)$ & -1.94 & -3.73 & 0.1807 & $\mathrm{~N}$ \\
\hline $\operatorname{lnM} 2$ & $(\mathrm{c}, 0,3)$ & -0.86 & -3.08 & 0.0727 & $\mathrm{Y}$ \\
\hline GDPE & $(\mathrm{c}, \mathrm{t}, 3)$ & -2.60 & -3.73 & 0.2835 & $\mathrm{~N}$ \\
\hline $\ln$ GDPE & $(\mathrm{c}, 0,3)$ & -3.85 & -3.04 & 0.0216 & $\mathrm{Y}$ \\
\hline GDPM & $(\mathrm{c}, \mathrm{t}, 4)$ & -5.19 & -3.73 & 0.1057 & $\mathrm{~N}$ \\
\hline $\operatorname{lnGDPM}$ & $(\mathrm{c}, 0,4)$ & -2.60 & -3.04 & 0.0613 & $\mathrm{Y}$ \\
\hline GDPW & $(\mathrm{c}, \mathrm{t}, 4)$ & -2.80 & -3.69 & 0.2117 & $\mathrm{~N}$ \\
\hline $\operatorname{lnGDPW}$ & $(\mathrm{c}, 0,4)$ & -3.85 & -3.04 & 0.0439 & $\mathrm{Y}$ \\
\hline CPIE & $(\mathrm{c}, \mathrm{t}, 4)$ & -3.09 & -3.05 & 0.0462 & $\mathrm{~N}$ \\
\hline $\operatorname{lnCPIE}$ & $(\mathrm{c}, 0,4)$ & -4.29 & -3.05 & 0.0045 & $\mathrm{Y}$ \\
\hline CPIM & $(\mathrm{c}, \mathrm{t}, 4)$ & -2.87 & -3.05 & 0.0694 & $\mathrm{~N}$ \\
\hline $\operatorname{lnCPIM}$ & $(\mathrm{c}, 0,4)$ & -4.14 & -3.05 & 0.0041 & $\mathrm{Y}$ \\
\hline CPIW & $(\mathrm{c}, \mathrm{t}, 4)$ & -3.8 & -3.05 & 0.0119 & $\mathrm{~N}$ \\
\hline $\operatorname{lnCPIW}$ & $(\mathrm{c}, 0,4)$ & -5.19 & -3.02 & 0.0006 & $\mathrm{Y}$ \\
\hline
\end{tabular}

\section{Granger Test}

We use Granger test to explore the relationship between monetary policy variables and regional output and price variables is tested. The results show that the difference variables are stationary variables, the results of the Granger causality test based on the stationary difference variables are shown in table 2 .

Table 2. Granger causality test results

\begin{tabular}{|c|c|c|c|}
\hline Hypothesis & F value & P value & result \\
\hline LNM2 does no Granger Cause LNGDPE & 5.2843 & 0.0219 & accept \\
LNM2 does no Granger Cause LNCPIE & 3.5069 & 0.0605 & accept \\
\hline LNM2 does no Granger Cause LNGDPM & 12.3011 & 0.0010 & accept \\
LNM2 does no Granger Cause LNCPIM & 13.6981 & 0.0002 & accept \\
\hline LNM2 does no Granger Cause LNGDPW & 0.8376 & 0.6490 & reject \\
LNM2 does no Granger Cause LNCPIW & 17.0671 & 0.0003 & accept \\
\hline
\end{tabular}

\section{Modeling}

According to the proxy variables we selected: the broad money supply (M2), the gross domestic product (GDP) and the consumer price index (CPI), we construct the VAR model of three regions in China

$$
\begin{aligned}
& Y_{1 t}=[d \ln G D P E, d \ln C P I E, d \ln M 2] \\
& Y_{2 t}=[d \ln G D P M, d \ln C P I M, d \ln M 2]
\end{aligned}
$$




$$
Y_{3 t}=[d \ln G D P W, d \ln C P I W, d \ln M 2]
$$

First of all, the lag coefficients of VAR model in three regions should be determined. Due to the small sample size of this paper, on the one hand, we should consider the lag order can better show the dynamic characteristics of the model, on the other hand to consider the freedom of the model. By using the Eviews8.0 software to calculate the judgment, the maximum lag order of three regions is all 4 .

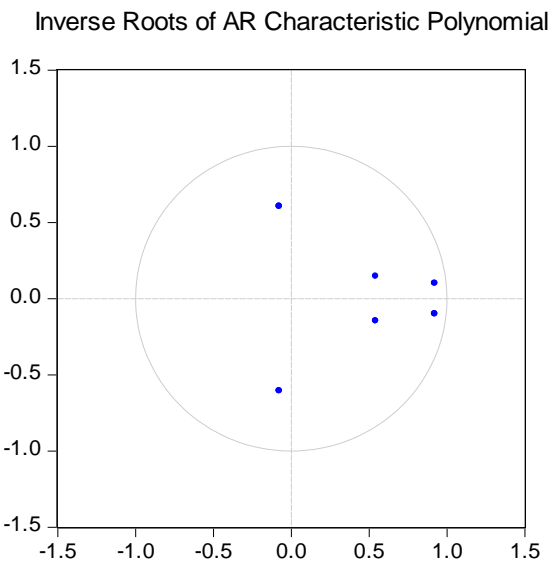

Figure1. AR root in eastern

Inverse Roots of AR Characteristic Polynomial

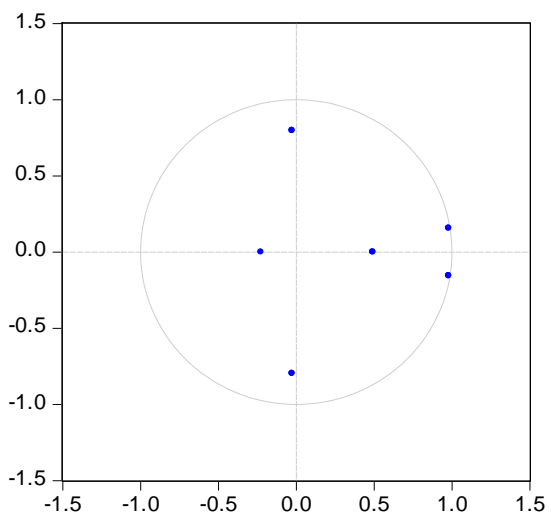

Figure2. AR root in middle

Inverse Roots of AR Characteristic Polynomial

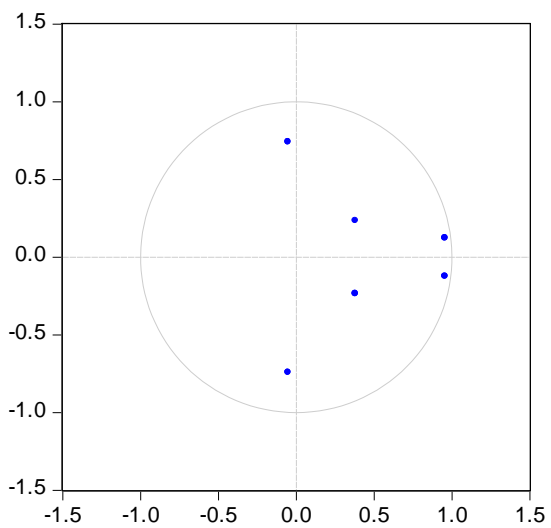

Figure3. AR root in weastern

As shown in Figure 1, Figure 2 and Figure 3, the points of the three VAR models are all within the unit circle, and the reciprocal of all the roots of the estimated model is less than 1, which shows that the three VAR models satisfy the stability conditions. 


\section{Impulse Response Function Analysis}

Based on the VAR model, the impulse response function reflect the size of each region's output and price shocks to monetary policy, and the time delay and time distribution. The figure 4, Figure 5 and Figure 6, the impact of monetary policy shocks on the price of the impulse response diagram in three regions.

We first analyses the impact of monetary policy on GDP. From the overall trend, the three regions are basically consistent, so that the effect of the national monetary for difference regions is almost the same, the difference is the magnitude of the impact of the three regions. From the graph, the impulse response function of the output of the three regions is zero at first. In the effect of monetary policy, the middle of the output response function of the fastest rising, the highest point in fifth to six stage, and then began to fall back to the lowest point in the ninth stage, and then tends to be stable. Although the impulse response of the output to the monetary policy in the western region is similar to that in the eastern part of the country, the change is far from that of the other two regions. This indicates that the implementation of China's monetary policy is effective, and the transmission of monetary policy in different regions is different, the output pulse effect in eastern and middle parts of China is lager than in western region.

Analysis of the impact of monetary policy on CPI: From the impulse response function of the price level of the three regions to the monetary policy, the price impulse response function of the three regions is almost zero in the beginning. When monetary policy is implemented, the middle region is the strongest, followed by the eastern region, the western region is still the slowest. As we can see in the figure, in the effect of monetary policy, the impulse response function of the three area before the two values are rising rapidly, reached a small peak, middle reflect particularly acute the highest value reached about 20, and the price of the impulse response function value is only the middle reflect $1 / 10$, this shows that monetary policy will stimulate the rapid growth of the price level in the short term. After the performance, the curve and the rapid decline in the six to seven period return to zero. After the eastern rebound, while the middle and Western to negative.

Response of GDPE to M2
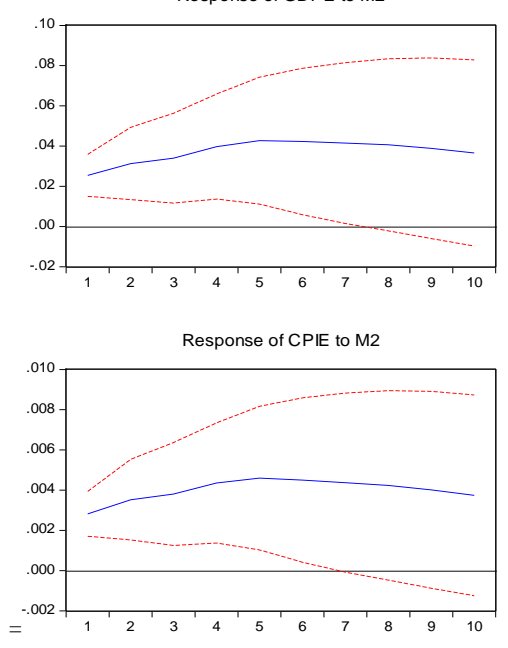

Figure4. response of GDPE to M2 

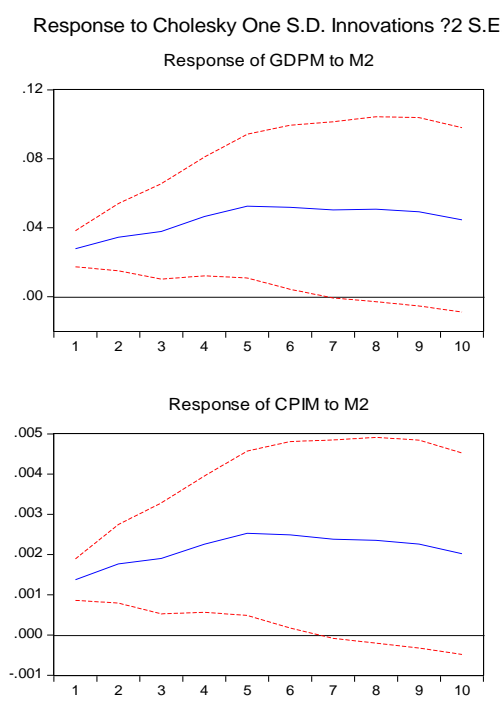

Figure5. response of GDPM to M2

Response to Cholesky One S.D. Innovations ?2 S.E. Response of GDPW to M2
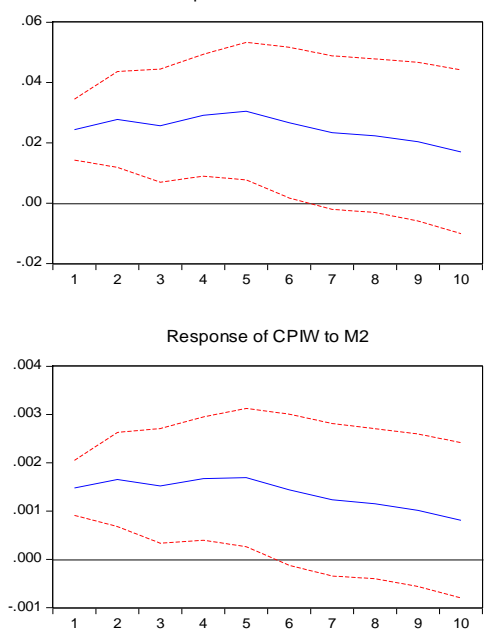

Figure6. response of GDPW to M2

\section{Summary}

In the pulse analysis, we find that both the impact on the output or the price, the reaction in the middle is higher than the eastern part, which is in contradiction with the conclusions drawn from the theoretical research. The reason lies in:

First, as a developed region, the nature of the enterprise is more capital intensive and state-owned enterprise, while the less developed area is more labor intensive. Therefore, the former has a more perfect means of financing and financing channels, the more perfect information channels and financing costs, faster response to monetary policy, lower dependence. The latter is mainly composed of labor-intensive industries, a high degree of dependence on financing, very sensitive to changes in the environment.

Developed regions have more mature and better economic results and industrial structure, so the impact of monetary policy shocks faster and better response mechanism, leading to the financial friction in the eastern region is also smaller.

First of all, in the framework of a unified monetary policy, according to the different regions of the economic development of the differences in the choice of cameras, combined with the development of regional differences in the development 
of regional monetary policy objectives. Secondly, we should improve the financial system and speed up the adjustment of industrial structure in the middle and Western regions. In addition, we should learn from foreign experience.

\section{References}

[1] Zhu, Ling Ling, R. D. Hu, and X. H. Su. "Analysis on the industrial restructuring effect of China's monetary policy — Based on VAR model."International Conference on Business Management and Electronic Information IEEE, 2011:58 - 61.

[2] Qiu, Bin, and Y. Deng. "Research on the Asymmetric Regional Effects of Monetary Policy in China Based on the VAR Model." South China Finance(2009).

[3] Zhang, Jing. "The Regional Effect of Chinese Monetary Policy and its Reasons_-An Empirical Analysis under Structure VAR Model." Journal of Guangdong University of Finance (2006).

[4] He, Lina. "An Empirical Analysis on the Asymmetric Regional Effects of Chinese Monetary Policy: Based on the VAR Models of Jiangsu and Henan Province." First IEEE International Conference on Information Science and Engineering IEEE Computer Society, 2009:4180-4183.

[5] Luciani, Matteo. "A VAR Model for the Analysis of the Effects of Monetary Policy in the Euro Area." Conservation Biology 22.22(2004):1659-61. 